\author{
Kateryna Laidler \\ Maria Curie-Skłodowska University \\ Pl. Marii Curie-Skłodowskiej 4a \\ 20-031 Lublin, Poland
}

\title{
Ukrainian Obstruent + Sonorant and Sonorant + Obstruent Consonant Clusters in Online Adaptation by Native Speakers of English
}

\begin{abstract}
In the process of loanword adaptation words often undergo various changes in order to comply with the phonological system of the borrowing language. At the phonotactic level the most commonly applied modifications of alien consonant clusters include vowel insertion, consonant deletion and cluster modification. The present paper examines online adaptation of Ukrainian word-initial twoconsonant sequences of radically different segmental makeup and sonority relations, namely, obstruent + sonorant (e.g. /zm/, /vn/) and sonorant + obstruent (e.g. /rt/, /mz/), which are illicit in English, in order to establish the major phonological patterns of anglicization and account for them in the light of Optimality Theory.

Keywords: loanword adaptation; Ukrainian consonant clusters; obstruent; sonorant
\end{abstract}

1. Introduction

In recent years the issue of loanwords has been in the centre of those phonological investigations which attempt to uncover and analyse the mechanisms underlying the transfer of a word from one language to 
another, i.e. loanword adaptation processes. Perhaps one of the most interesting questions which loanword phonology is concerned with is how speakers of a particular language adapt words containing sounds or sound sequences which do not exist in their native language.

In the process of loanword adaptation the words that are borrowed invariably undergo certain modifications so as to comply with the phonological rules of the recipient language. For instance, if a loanword contains clusters disallowed in the target system, some changes are bound to occur. The most frequent strategies that are used to ensure this compliance at the phonotactic level are vowel insertion, consonant deletion and cluster modification, with the first being the most common one. However, it is often claimed that the choice of a particular repair strategy is a matter of perspective only. For example, when a word with a CC cluster is borrowed into the language with a ban on such clusters, the requirements of a target language can be satisfied either by deleting one of the consonants or by inserting a vowel. Take a Polish place name Gdańsk which begins with a cluster of two plosives /gd/ not found in word-initial position in English. According to Wells (2008: 335), two versions are used in English, i.e. [dænsk], with the deletion of the initial /g/ and [gə'dænsk], where schwa is inserted between the two consonants. The question that arises is which of these strategies is more common and what factors determine their choice.

Evidence from phonological experiments presented by Kang (2011) shows that epenthesis is frequently employed in languages which do not allow complex onsets when illicit clusters are found word-initially, for example, in Japanese, Korean or Arabic. According to Paradis and LaCharite's (1997) theory of Constraints and Repair Strategies (TCRS), the Preservation Principle will resist the loss of segments, making insertion a preferred repair strategy. However, in the investigation of English loanwords in Marshallese, Brasington (1997) argues that the choice between epenthesis and deletion is not influenced exclusively by the cost of the repair of an illicit sequence. It is the position of a cluster that primarily governs the choice of the adaptation strategy. Thus, when Marshallese borrows from English, 
epenthesis dominates in initial clusters, while complex codas are repaired by deletion. The same research shows that another factor to consider is the cluster's make-up since word-final nasal + homorganic stop clusters are predominantly repaired by deletion, whereas the adaptation of lateral + obstruent codas is equally distributed between epenthesis and elision. Therefore, the choice of a repair strategy may be influenced by a number of factors including the position of a cluster, its structure or the channel of borrowing (written or spoken).

In this paper we report on an online adaptation experiment in which 25 native speakers of British English were asked to reproduce 37 Ukrainian words containing CC consonant clusters which do not occur in English. Some aspects of this issue have been discussed by Radomski \& Sydorenko (2016). In what follows we focus on the adaptation of word-initial CC consonant clusters of radically different segmental make-up and sonority relations, namely sequences of obstruent + sonorant and sonorant + obstruent.

Even though the notion of sonority is widely used in modern phonological literature to explain various phonotactic tendencies, there is no agreement as to how to define and measure sonority of an individual sound. First described by Sievers (1885) as a relative loudness of a speech sound compared to other sounds, it has given rise to the idea of the sonority hierarchy and the Sonority Sequencing Generalisation (SSG) (Steriade 1982, Selkirk 1984, Clements 1990). The SSG, which is based on the sonority hierarchy (with stops assumed as the least sonorous, followed by fricatives, nasals, liquids, semivowels and vowels), defines the shape of a well-formed syllable, in which more sonorous consonants are located closer to the peak of sonority (usually a vowel), while the less sonorous ones are placed further away from it. This principle allows us to make certain predictions as to which sequences are more likely to be found in a language even without any prior knowledge about its phonotactic constraints. To give an example, a sequence [græmp] is more likely to 
occur than, for instance, [rgæmp] or [græpm] simply because the first one is a better formed syllable according to the SSG principle. ${ }^{1}$

In this paper we aim to answer the following research questions:

- Does the sonority profile of word-initial Ukrainian CC clusters determine the rate of target-like reproductions by native speakers of English?

- What are the differences in the choice or repair strategies in the case of obstruent + sonorant and sonorant + obstruent clusters?

- How can the adaptation patterns be accounted for within the model of Optimality Theory?

We start with the description of the experimental design in Section 2. Section 3 focuses on the results of the experiment which provide answers to the first two research questions. An OT analysis of the patterns uncovered by the data presented in Section 4 addresses the last question. Conclusions are drawn in Section 5 of this paper. For the reason of space, we do not present the detailed description of OT framework. However, it should be mentioned that Optimality Theory has been used extensively to successfully account for the phonological processes in loanword adaptations. Since the process of adaptation implies the derivation of a sound from the underlying form in the source language to a surface one in the borrowing language, OT with its universal phonological constraints can be applied.

\section{Experimental design}

This section of the paper deals with the most essential aspects of the experimental design. We describe the stimuli, the participants and the experimental set-up. Finally, an explanation of the major principles underlying the classification and analysis of the data is provided.

\footnotetext{
${ }^{1}$ In some approaches, such as Government Phonology or Natural Phonology, the SSG is rejected. A number of other parameters are utilised instead in order to explain such phonotactic preferences, e.g. perceptual distance, manner or place of articulation, or the combination of all three.
} 
Ukrainian Obstruent + Sonorant and Sonorant + Obstruent ...

\subsection{Stimuli}

The experimental stimuli consisted of 70 authentic Ukrainian words containing word-initial CC consonant clusters of different types. This paper, however, will focus on two groups of ill-formed clusters found in 27 Ukrainian words which include the following:

- 16 items with obstruent + sonorant clusters, which comprise sequences of fricative + lateral as in [zlada] 'accordance', fricative + nasal, as in [zmalku] 'from early age', plosive + nasal, as in [gmax] 'building' and plosive + lateral, as in [dliatI] 'do sth slowly';

- 11 items with sonorant + obstruent clusters, which were represented by nasal + affricate as in [mtgatı] 'dash', nasal + fricative, as in [mzitI] 'drizzle', glide + plosive, as in [jtis a] 'be about' and nasal + plosive, as in [nganas] 'creature'.

14 distractors, all of which were monosyllabic Ukrainian words that did not include any segmental or phonotactic structures disallowed in English, were also included in the experimental material. The order of the stimuli was randomised to avoid sequences of clusters with a similar quality. They were recorded by a female native speaker of Ukrainian with 3-5 second intervals between them. The recording was made using the Samson CO1U USB Studio Condenser microphone.

\subsection{Participants}

The participants of the experiment were 25 native speakers of British English, aged 25-32, including 12 males and 13 females. Some of them were students at the University of Sussex while others have successfully obtained their degrees and now work as teachers of English, bank clerks, sales executives etc. This means that all of them had college education and spoke a variety generally described as Educated Southern British English. None of the participants had any knowledge of Ukrainian or any other Slavic languages. Neither of them reported any hearing or speech production difficulties. 
2.3. Procedure and data classification

The task involved the reproduction of the recorded Ukrainian words by the participants who did not know which language they were taken from. However, prior to the administration of the experiment they were warned not to expect to hear English words. The test was performed with one person at a time and the recording was manually operated. This means that the experimenter could give the subjects as much time as they needed to listen to each of the items and then repeat it. The stimuli were presented through Sennheiser PC360 headphones. The responses were analysed auditorily as well as with the aid of wide-band spectrograms, which were created with Speech Analyzer 3.1 software.

The data obtained in the experiment were classified into four categories. In the case when the reproduced clusters showed insignificant or no difference from the stimuli items, they were placed in the 'target-like pronunciation' group. Vowel epenthesis was recognised when a segment which was inserted between the consonants of a cluster had a duration of at least $20 \mathrm{~ms}$. In most instances an epenthetic vowel produced by the speakers was easily distinguished auditorily. Predominantly, illicit consonant sequences were repaired by inserting [ซ], [I] or [ə]-like vowels ${ }^{2}$, for example, $/ \mathrm{mz} /, / \mathrm{mg} /$ and $/ \mathrm{gm} /$ were most frequently changed into [mI3], [motf] and [gəm] respectively. The clusters with one of the elements being absent were placed in the 'deletion' group. Even though the examples of this repair strategy include cases of elision of either of two consonants, it is the first of them that was predominantly deleted by the participants, e.g. $/ \mathrm{vn} />[\mathrm{n}], / \mathrm{r} />$ [3]. Finally, for a cluster to be diagnosed as 'modified', voicing, the place or manner of articulation of either of the two consonants had to be changed. Modifications which resulted in both legal and non-legal English clusters were included into this category. The participants usually changed the first consonant in a cluster and the most frequent modifications included

${ }^{2}$ In the majority of cases the participants produced some kind of a centralised vowel of unidentified quality typical for Vowel Reduction in British English. 
$/ \mathrm{tl} /$ to $[\mathrm{pl}], / \mathrm{dl} /$ to [pl] and $/ \mathrm{jt} /$ to [It]. If the responses did not qualify for any of the above-mentioned types, they were placed under the fifth category named 'other'.

\section{Results}

\subsection{Obstruent + sonorant clusters}

Target-like production occurred in 10 out of 15 clusters within this group with $50 \%$ or more participants reproducing many of the sequences correctly. Such a high overall rate of target-like productions $(41 \%)$ leads to the conclusion that the pronunciation of obstruent + sonorant clusters does not create any particular difficulty for native speakers of English even if such sequences are absent in this language. The data are presented below in Figure 1.

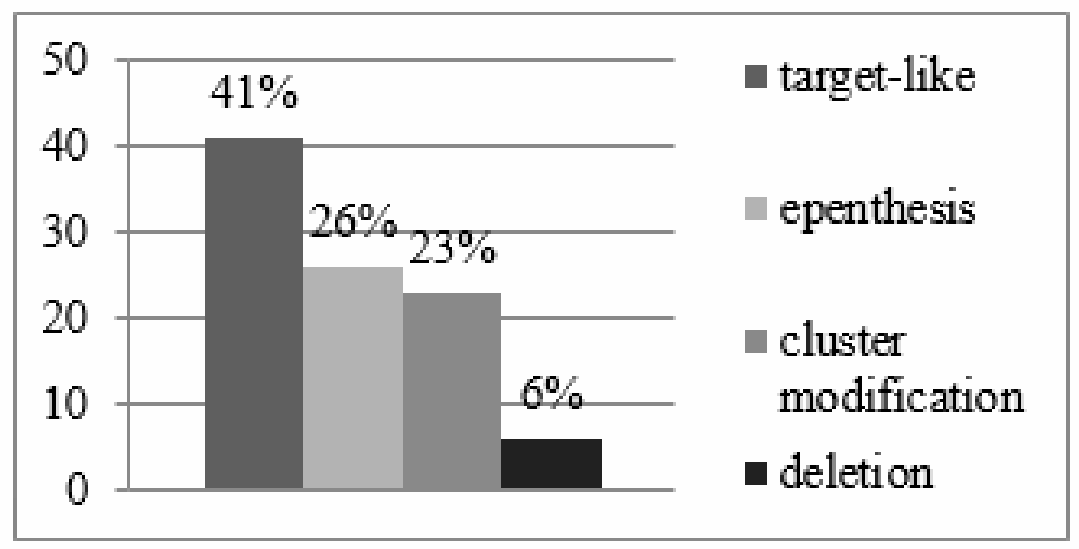

Figure 1. Results for obstruent + sonorant clusters

Figure 1 shows that target-like productions $(41 \%)$ dominate over two repair strategies, i.e. epenthesis $(26 \%)$ and cluster modification (23\%). Consonant deletion occurs only in $6 \%$ of cases.

The behaviour of individual clusters within this group and the percentage of their correct reproductions are shown in Table 1. 
Table 1. The results for individual clusters within the obstruent + sonorant group

\begin{tabular}{|c|c|c|c|c|}
\hline & Target-like & Epenthesis & Deletion & $\begin{array}{c}\text { Cluster } \\
\text { modification }\end{array}$ \\
\hline$/ \mathrm{zl} /$ & $64 \%$ & $12 \%$ & $8 \%$ & $16 \%$ \\
\hline$/ \mathrm{zm} /$ & $60 \%$ & $28 \%$ & $4 \%$ & $8 \%$ \\
\hline$/ \mathrm{zn} /$ & $56 \%$ & $20 \%$ & $0 \%$ & $20 \%$ \\
\hline$/ \mathrm{gm} /$ & $36 \%$ & $36 \%$ & $4 \%$ & $20 \%$ \\
\hline$/ \mathrm{dl} /$ & $24 \%$ & $32 \%$ & $12 \%$ & $28 \%$ \\
\hline$/ \mathrm{sr} /$ & $48 \%$ & $28 \%$ & $8 \%$ & $16 \%$ \\
\hline$/ \mathrm{tl} /$ & $24 \%$ & $4 \%$ & $0 \%$ & $72 \%$ \\
\hline$/ \mathrm{vn} /$ & $24 \%$ & $44 \%$ & $20 \%$ & $8 \%$ \\
\hline$/ \mathrm{vm} /$ & $56 \%$ & $16 \%$ & $0 \%$ & $28 \%$ \\
\hline$/ \mathrm{dm} /$ & $40 \%$ & $16 \%$ & $8 \%$ & $24 \%$ \\
\hline$/ \mathrm{dn} /$ & $16 \%$ & $40 \%$ & $4 \%$ & $32 \%$ \\
\hline$/ \mathrm{tn} /$ & $24 \%$ & $48 \%$ & $4 \%$ & $16 \%$ \\
\hline$/ \mathrm{xr} /$ & $48 \%$ & $24 \%$ & $0 \%$ & $16 \%$ \\
\hline$/ \mathrm{vl} /$ & $48 \%$ & $32 \%$ & $20 \%$ & $0 \%$ \\
\hline$/ \mathrm{gn} /$ & $40 \%$ & $28 \%$ & $8 \%$ & $24 \%$ \\
\hline
\end{tabular}

An accurate imitation very often reaches almost $50 \%$ or even more with, for example, /zl/ being produced correctly by $64 \%$ of the participants $/ \mathrm{zm} /$ by $60 \%$, /zn/ by $56 \%$ and $/ \mathrm{vm} /$ by $56 \%$. Such a successful reproduction of the consonant sequences can be accounted for by their conformity to the sonority profile of a well-formed syllable onset. Even though consonant sequences in this group of stimuli are illegal in word-initial position in English, their sonority increases, which can explain the ease with which these clusters were imitated.

In the case of the sequences that were repaired mainly by epenthesis, a vowel is most frequently inserted in the combination of stop + nasal: $/ \mathrm{gm} /-36 \%, / \mathrm{dn} /-40 \%, / \mathrm{tn} /-48 \%$. On the other hand, the clusters with a fricative in the initial position are reproduced more faithfully. Out of 8 such sequences $7^{3}$ were predominantly reproduced

${ }^{3}$ The only fricative + sonorant combination whose major repair strategy was different is /vn/, with $44 \%$ of the participants adapting it with vowel epenthesis. 
in a target-like fashion (/zl/, /zm/, /zn/, /sr/, /vm/, /xr/, /vl/). Moreover, only 3 clusters which were produced accurately by the majority of participants present a different segmental make-up: /gm/, /dm/ and /gn/. The percentage of the target-like production for the latter group does not reach more than $40 \%$, whereas fricative + sonorant combinations were imitated accurately by at least $48 \%$ of the subjects. Thus, the manner of articulation of the elements of a cluster can largely predict the choice of the repair strategy. The sequences of stop + nasal are frequently repaired by vowel insertion, while clusters beginning with a fricative are produced more successfully. A possible explanation of such a pattern is that a fricative + sonorant (where the fricative is voiceless) are common combinations in English, e.g. in smoke, shrimp, slow, fly. Moreover, some of these clusters appear in borrowings, e.g. [zl] > zloty; [sr] > Sri Lanka.

The third strategy is cluster modification with $23 \%$ of all repairs applied by the participants. The clusters that were most frequently modified in this way include $/ \mathrm{tl} /-72 \%, / \mathrm{dn} /-32 \%, / \mathrm{vm} /-28 \%, / \mathrm{dl} /-$ $28 \%, / \mathrm{dm} /-24 \%$ and $/ \mathrm{gn} /-24 \%$. When a closer look is taken at these sequences, it can be noticed that plosive + sonorant clusters $(/ \mathrm{dl} /, / \mathrm{tl} /$, $/ \mathrm{dn} /, / \mathrm{dm} /, / \mathrm{gm} /$ ) undergo modifications more frequently than fricative + sonorant $(/ \mathrm{vm} /)$. Moreover, with regard to the place of articulation, the majority of repairs are found among alveolar plosive + sonorant $(/ \mathrm{dl} /, / \mathrm{t} \mathrm{l} /, / \mathrm{dn} /, / \mathrm{dm} /)$ sequences.

Deletion is generally dispreferred and the patterns of its use are rather inconsistent. The only 2 clusters in which one of the consonants was deleted by $20 \%$ of the participants are $/ \mathrm{vn} /$ and $/ \mathrm{vl} /$.

Even though the predominant repair strategy can be established for each of the clusters, in the majority of cases two or sometimes three different types of adaptation are employed. Thus, clusters whose production is almost equally divided among three different strategies include $/ \mathrm{gm} /, / \mathrm{dl} /, / \mathrm{gn} /$ and $/ \mathrm{vl} /$. There are also a number of clusters which are adapted by means of one dominant strategy, but the other two are also frequently employed, like in the case of $/ \mathrm{xr} /, / \mathrm{dn} /, / \mathrm{dm} /$, $\mathrm{zm} /, / \mathrm{vm} /$ or $/ \mathrm{tn} /$. Such lack of uniformity in the choice of repair strategies by native speakers shows that in some instances more than 
one choice is possible, which an adequate analysis should be able to account for.

3.2. Sonorant + obstruent clusters

The results showing the realizations of sonorant + obstruent clusters are presented in Figure 2.

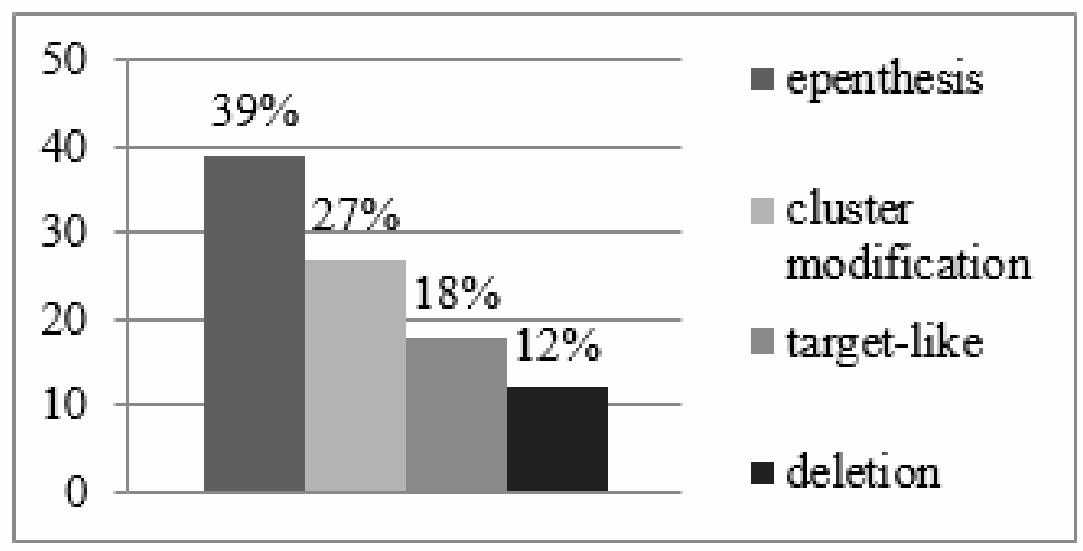

Figure 2. Results for sonorant + obstruent clusters

As shown in Figure 2, the most common types of repairs within this group of clusters involve vowel epenthesis and cluster modifications (39\% and $27 \%$ respectively). The number of target-like productions is considerably lower compared to obstruent + sonorant sequences and amounts only to $18 \%$. This is not surprising considering that clusters in this group do not appear in English at all. Deletion is infrequent with an exception of a few clusters $(/ \mathrm{rv} /, / \mathrm{r} 3 /$ and $/ \mathrm{jv} /$ ) which were repaired this way more often than others.

As in the case of obstruent-sonorant clusters, the sonority profile can largely account for the results in this group. The falling sonority found in them violates the structure of syllable onsets expressed by the SSG. The fact that the majority of clusters are repaired by inserting an epenthetic vowel between the consonants (7 clusters out of 11) is in 
line with the findings on illusory vowels presented by Dupoux, Parlato, Frota, Hirose \& Peperkamp (2011). A number of experiments have shown that speakers of different languages tend to perceive an illusory vowel inside consonant clusters if those are illegal in their native language. A more detailed presentation of the behaviour of individual clusters is shown in the table below.

Table 2. The results for individual clusters within the sonorant + obstruent group

\begin{tabular}{|c|c|c|c|c|}
\hline & Target-like & Epenthesis & Deletion & $\begin{array}{c}\text { Cluster } \\
\text { modification }\end{array}$ \\
\hline$/ \mathrm{mg} /$ & $12 \%$ & $64 \%$ & $12 \%$ & $8 \%$ \\
\hline$/ \mathrm{m} 3 /$ & $12 \%$ & $56 \%$ & $12 \%$ & $12 \%$ \\
\hline$/ \mathrm{rv} /$ & $24 \%$ & $40 \%$ & $20 \%$ & $12 \%$ \\
\hline$/ \mathrm{l} /$ & $8 \%$ & $56 \%$ & $4 \%$ & $24 \%$ \\
\hline$/ \mathrm{rd} /$ & $20 \%$ & $52 \%$ & $8 \%$ & $20 \%$ \\
\hline$/ \mathrm{r} /$ & $8 \%$ & $44 \%$ & $32 \%$ & $16 \%$ \\
\hline$/ \mathrm{jt} /$ & $12 \%$ & $16 \%$ & $8 \%$ & $64 \%$ \\
\hline$/ \mathrm{rt} /$ & $22 \%$ & $40 \%$ & $8 \%$ & $30 \%$ \\
\hline$/ \mathrm{ng} /$ & $8 \%$ & $20 \%$ & $8 \%$ & $48 \%$ \\
\hline$/ \mathrm{lv} /$ & $52 \%$ & $36 \%$ & $0 \%$ & $8 \%$ \\
\hline$/ \mathrm{jv} /$ & $12 \%$ & $16 \%$ & $20 \%$ & $52 \%$ \\
\hline
\end{tabular}

The participants most frequently applied vowel insertion to repair the following clusters: /rv/, //3/, /rz/, /lv/, /mg/, /mz/, /rd/ and /rt/. The majority of these combinations (except for $/ \mathrm{rd} /$ and $/ \mathrm{rt} /$ ) are the sequences of sonorant + fricative, where the first element is often a liquid. Several clusters from this group caused a particular difficulty, for example, $/ \mathrm{mtg} /$ which was repaired by $64 \%$ of the participants with the most frequent adaptation being [mət]], /mz/ and $/ 13 /$ which were often pronounced as [mə3] and [1ə3], respectively.

With regard to cluster modification, which is the second largest group of adaptations amounting to $27 \%$, the majority ${ }^{4}$ of sequences

\footnotetext{
${ }^{4}$ The exceptions are /jv/ - 52\% and /l3/ $-25 \%$
} 
repaired in this way consist of sonorant + plosive: /jt/ - 64\%, /ng/ $48 \%, / \mathrm{rt} / \mathrm{-30 \%}, / \mathrm{rd} / \mathrm{-2}$ - 20\%. In other words, all sonorant + obstruent sequences where the second element is a plosive are often repaired by means of cluster modification.

Interestingly, in both clusters with the initial palatal glide, this element was modified by the vast majority of the participants $(64 \%$ and 52\%). In most cases $/ \mathrm{j} /$ was pronounced as the vowel [I]. This might be connected with the fact that in English the consonant $/ \mathrm{j} /$ is restricted to positions adjacent to a vowel, hence creating a considerable difficulty for English native speakers when followed by another consonant.

Only $18 \%$ of the responses were classified as target-like. The cluster that was produced most successfully in this group is $/ \mathrm{lv} /$ with $52 \%$ of target-like responses. It is likely, however, that such an ease with which it was reproduced is connected with the word it was used in, which was /lvi:v/, the name of a city in the Ukraine. It might be that some of the speakers were familiar with it or at least had heard it before, which could help in recognising and thus producing the sequence. However, if a closer look is taken at the target-like productions, it becomes obvious that some clusters, even though they were mainly modified by means of epenthesis, still posed less difficulty to native speakers than others. Thus, /rv/ was produced accurately by $24 \%$ of the participants, $/ \mathrm{rt} /$ by $22 \%$ and $/ \mathrm{rd} /$ by $20 \%$. All these clusters start with $/ \mathrm{r} /$, which is produced as a trill in Ukrainian, and is therefore perceptually noisy. It can be assumed that its perceptual salience strengthens native speakers' determination to pronounce a rhotic in this context.

Deletion is the least common adaptation strategy, with only $12 \%$ of the participants employing it in the repair of some illicit clusters. Only in the case of three sequences elision was used more often than usual: $/ \mathrm{r} 3 /-32 \%, / \mathrm{rv} /-20 \%, / \mathrm{jv} /-20 \%$. In all these sequences approximants are followed by voiced fricatives. 
The clusters in the sonorant + obstruent group fall into three types with regard to the number of adaptation strategies employed by the participants ${ }^{5}$ :

1 strategy: /mtg/, /mz/, /jt/;

2 strategies: //z/,/rz/, /ng/, /lv/, /jv/;

3 strategies: $/ \mathrm{rd} /, \mathrm{/rt} /, / \mathrm{rv} /$.

The majority of nasal + obstruent sequences are repaired by means of only one adaptation strategy, mainly vowel epenthesis. On the other hand, the participants reach for two different strategies to adapt liquid + fricative sequences. Finally, the combinations in whose repair three different strategies were used mainly include $r+$ dental plosive.

3.3. Summary of the results

The table below summarises the results for the major repair strategies employed in the adaptation of obstruent + sonorant and sonorant + obstruent clusters.

Table 3. Summary of the results

\begin{tabular}{|c|c|c|}
\hline STRATEGY & obstruent + sonorant & sonorant + obstruent \\
\hline target-like & $41 \%$ & $18 \%$ \\
\hline vowel epenthesis & $26 \%$ & $39 \%$ \\
\hline cluster modification & $23 \%$ & $27 \%$ \\
\hline consonant deletion & $6 \%$ & $12 \%$ \\
\hline
\end{tabular}

The table reveals the major similarities and differences in the use of adaptation strategies. There is an obvious contrast in the frequency of target-like productions and repairs by means of epenthesis between the two groups of clusters. Thus, obstruent + sonorant sequences are produced in a target-like fashion in $41 \%$ of cases, while vowel insertion is applied in $39 \%$ of sonorant + obstruent clusters. The rate of cluster modifications is very similar for both types and consonant

${ }^{5}$ Only the instances where repair strategy was applied by $20 \%$ of the participants or more were taken into account. 
deletion is the rarest strategy for all analysed sequences. Moreover, it can also be noticed that in the adaptation of obstruent + sonorant sequences 3 main strategies are employed (target-like $>$ epenthesis $=$ cluster modification), whereas for sonorant + obstruent ones native speakers mainly choose between two types of repairs (epenthesis > cluster modification).

\section{Analysis}

The patterns of cluster adaptation discussed in the preceding sections are analysed in terms of Optimality Theory below.

Let us first consider the main adaptation strategies employed by the majority of the participants in the case of the obstruent + sonorant group. Target-like productions will be analysed with the example of /zl/; /gm/ which was frequently adapted as [gəm] will serve as an instance of epenthesis; /tl/ with its major change into [pl] will be used to illustrate cluster modification.

In order to account for these repairs several faithfulness constraints proposed by McCarthy \& Prince (1995) will be employed:

$D E P-I O$ - output segments must have input correspondents. ('No epenthesis')

$M A X-I O$ - input segments must have output correspondents. ('No deletion')

IDENT (place) - input and output consonants have the same place of articulation.

IDENT (voice) - input and output obstruents have the same value for the feature [voicing]

IDENT (manner) - input and output consonants have the same manner of articulation.

IDENT (dorsal) - input and output consonants have the same value for feature [dorsal].

IDENT-IO-C - no consonant substitution.

A major restriction that must be employed is that syllables should not start in a sequence of consonants of falling sonority and end in clusters of rising sonority. This is a discussed earlier cross-linguistic phenomenon of the SSG formulated as a markedness constraint by Kager as follows (1999: 267): 
$S O N-S E Q$ - complex onsets rise in sonority, and complex codas fall in sonority.

However, yet another restriction must be applied to those syllable onsets that do not violate the above constraint. Clements (1990) ranks the distance between consonants by assigning points to each of them on the sonority scale: Obstruents (0) > Nasals (1) > Liquids (2) > Glides (3). According to the minimal sonority distance (Selkirk, 1984) principle, English requires the following OT constraint:

SONDIST - the minimal sonority distance for complex onsets must be at least 2 points.

This means that well-formed onsets cannot comprise consonants which are neighbours on the sonority scale.

In order to account for cluster modifications, for example, /t $1 /$ into [pl], (the cluster is well formed according to the SSG and the sonority distance between its segments is 2 points), the notion of the Obligatory Contour Principle (OCP), discussed by McCarthy (1986), must be employed. The effect of the OCP is a prohibition of the adjacent segments with identical specifications, which can be formulated as an OT constraint:

$O C P P L$ - adjacent identical major place features are prohibited. (Lin, 2005)

Let us now employ these constraints to the analysis of the most frequent repair strategies of obstruent + sonorant clusters. The tableaux for reasons of space include only the relevant constraints and the evaluation of selected candidates. As mentioned before, such clusters were often produced correctly by the majority of the participants in spite of their ill-formedness. Such a tendency indicates that many speakers rank faithfulness constraints over the markedness ones. For example, for /zl/, which was produced correctly in numerous cases, the ranking of the constraints can be the following: MAX-IO >> DEP-IO > IDENT (voice) > OCP PL.

\begin{tabular}{|c|l|l|l|l|}
\hline$/ \mathrm{zl} /$ & MAX-IO & DEP-IO & IDENT (voice) & OCP PL \\
\hline$\rightarrow$ a. $[\mathrm{zl}]$ & & & & $*$ \\
\hline b. $[\mathrm{z} ə \mathrm{l}]$ & & $*$ & & \\
\hline
\end{tabular}




\begin{tabular}{|l|l|l|l|l|}
\hline c. $[\mathrm{z}]$ & $*$ & & & \\
\hline d. $[\mathrm{l}]$ & $*$ & & & \\
\hline e. $[\mathrm{sl}]$ & & & $*$ & $*$ \\
\hline
\end{tabular}

Tableau 1.

The top ranking of the constraints MAX-IO and DEP-IO allows us to eliminate candidates (b), (c) and (d), which involve either epenthesis or consonant elision. Candidate (e) is ruled out by violating IDENT (voice), which makes (a) the optimal candidate, since, according to the ranking presented in Tableau 1, it violates the constraint which is ranked the lowest.

Let us now consider the most frequent repair of the $/ \mathrm{gm} / \mathrm{cluster}$. This sequence violates the principle of the minimal sonority distance and is often repaired by native speakers of English with an epenthetic vowel /ə/. In such a case, the preliminary ranking of the constraints for vowel epenthesis in $/ \mathrm{gm} /$ is SONDIST2 > IDENT (place) (manner) > MAX-IO >> DEP-IO.

\begin{tabular}{|c|l|l|l|l|}
\hline$/ \mathrm{gm} /$ & SONDIST2 & $\begin{array}{c}\text { IDENT (place) } \\
\text { (manner) }\end{array}$ & MAX-IO & DEP-IO \\
\hline a. $[\mathrm{gm}]$ & $* !$ & & & \\
\hline$\rightarrow$ b. $[\mathrm{g} ə \mathrm{~m}]$ & & & $*$ & $*$ \\
\hline c. $[\mathrm{g}]$ & & & $*$ & \\
\hline d. $[\mathrm{m}]$ & & & $*$ & \\
\hline e. $[\mathrm{gl}]$ & & $*$ & & \\
\hline
\end{tabular}

Tableau 2.

The faithful candidate (a) is eliminated by undominated SONDIST2. IDENT (place) (manner) rules out candidate (e) as well as any other potential one which will violate the constraint on place or manner identity. The other three candidates do not contain a complex onset and thus the most highly-ranked constraint is not applicable. However, candidates (c) and (d) violate MAX I-O by comprising only 
one segment. Thus, (b) with an epenthetic vowel becomes an optimal output candidate by violating the lowest-ranked constraint only.

The next most frequent repair strategy employed by the participants, cluster modification, will be analysed with an example of the /tl/ cluster.

\begin{tabular}{|c|l|l|l|l|l|l|}
\hline$/$ tll/ & OCP PL & $\begin{array}{c}\text { MAX- } \\
\text { IO }\end{array}$ & $\begin{array}{c}\text { DEP- } \\
\text { IO }\end{array}$ & $\begin{array}{c}\text { IDENT } \\
\text { (dorsal) }\end{array}$ & $\begin{array}{c}\text { IDENT } \\
\text { (manner) }\end{array}$ & $\begin{array}{c}\text { IDENT- } \\
\text { IO-C }\end{array}$ \\
\hline a.[tl] & $*$ & & & & & \\
\hline b.[tll] & & & $*$ & & & \\
\hline c.[t] & & $*$ & & & & \\
\hline d. [l] & & $*$ & & & & \\
\hline$\rightarrow$ e. [pl] & & & & & & $*$ \\
\hline f.[kl] & & & & $*$ & & \\
\hline g.[tr] & $*$ & & & & & \\
\hline h.[gl] & & & & $*$ & & \\
\hline i. [fl] & & & & & $*$ & \\
\hline
\end{tabular}

Tableau 3.

The following ranking of the constraints: OCP PL > MAX-IO >> DEP-IO $>$ IDENT (dorsal) > IDENT (manner) $>$ IDENT-IO-C allows us to eliminate candidates (a) and (g), which violate the most highly-ranked constraint OCP PL. Candidates (b), (c) and (d) cannot be considered optimal either as they go against faithfulness constraints which prohibit epenthesis and deletion respectively. Candidates (f) and (h) are also ruled out due to violating the specification for the feature [dorsal]. The most optimal output candidate (e) violates the lowest-ranked constraint while avoiding adjacent identical place features and showing the same value for feature [dorsal] as the input. IDENT (manner) allows us to rule out any potential candidates like (i), whose manner of articulation is different from that of the input plosive. 
The analysis of the most common repair strategies in sonorant + obstruent group demonstrates that the majority of native speakers rank faithfulness constraints higher than markedness ones when they encounter such illicit CC consonant clusters, which results in their more accurate reproduction. However, some speakers apply a different ranking, in which SONDIST2 or OCP PL are ranked over the faithfulness constraints and as a result different adaptation strategies are employed.

When it comes to sonorant + obstruent clusters, the most frequently applied repair strategies were epenthesis and cluster modification. Vowel insertion can be analysed using $/ \mathrm{mz} /$ as an example, which serves as an input to the production grammar. The interaction of the relevant constraints is shown in Tableau 4.

\begin{tabular}{|c|l|l|l|l|}
\hline \multicolumn{1}{|c|}{$/ \mathrm{m} /$} & SON-SEQ & $\begin{array}{c}\text { IDENT } \\
(\text { manner })\end{array}$ & MAX-IO & DEP-IO \\
\hline a. $[\mathrm{m} 3]$ & $* !$ & & & \\
\hline$\rightarrow$ b. $[\mathrm{mI}]$ & & & & $*$ \\
\hline c. $[\mathrm{m}]$ & & & $*$ & \\
\hline d. $[3]$ & & & $*$ & \\
\hline e. $[\mathrm{n}]$ & $* !$ & & & \\
\hline f. $[\mathrm{mj}]$ & & $*$ & & \\
\hline
\end{tabular}

Tableau 4.

Being the most highly ranked constraint, SON-SEQ rules out the faithful candidate (a). This leaves us with a number of other possible outputs for $/ \mathrm{mz} /$ : one of which requires epenthesis, two of them involve deletion of either of its segments, and the last two represent different types of modifications. The choice of epenthesis as a repair strategy over the two others logically possible ones, i.e. elision and cluster modification, shows that IDENT (manner) dominates faithfulness constraint MAX-IO, which is in its turn ranked higher than DEP-IO. 
Another strategy frequently applied by the participants to repair illicit sonorant + obstruent clusters was cluster modification. Let us consider the most commonly repaired sequence /jt/ in which the palatal glide was commonly vocalised. The same set of constraints will be applied with addition of the following:

IDENT (cons.) - input and output share specifications for the feature [consonantal] (McCarthy \& Prince, 1995).

IDENT (back) - input and output share specifications for the feature [back]. (Kager, 1999)

IDENT (low) - input and output share specifications for the feature [low]. (Kager, 1999)

IDENT (syllabic) - input and output share specifications for the feature [syllabic]. (McCarthy \& Prince, 1995)

*[-long,-stress][+stress] - only a [-long,-stress] syllable before a stressed syllable. (Hayes \& Wilson, 2008)

\begin{tabular}{|c|c|c|c|c|c|c|c|}
\hline /jt/ & 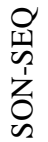 & 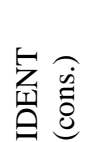 & 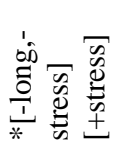 & 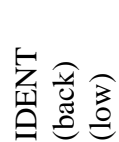 & $\frac{0}{\substack{x \\
\frac{1}{x}}}$ & $\frac{0}{1}$ & 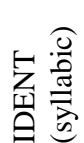 \\
\hline a. [jt] & $* !$ & & & & & & \\
\hline$\rightarrow$ b. [It] & & & & & & & * \\
\hline c. $[\mathrm{t}]$ & & & & & $*$ & & \\
\hline d. [j] & & & & & * & & \\
\hline e. [jot] & & & & & & * & \\
\hline f. [ji] & & * & & & & & \\
\hline g. [i:t] & & & * & & & & \\
\hline h.[चt] & & & & * & & & \\
\hline i. [æt] & & & & * & & & \\
\hline
\end{tabular}

Tableau 5.

With this set of constraints, we can immediately discard the faithful candidate (a) since it violates the undominated SON-SEQ; IDENT (cons.), on the other hand, rules out candidate (f) along with 
any other sequence in which the second element will involve the change of the feature [+consonantal] to [-consonantal]. Since the word with the cluster in question originally had stress on the first syllable, the change of its first element to a long vowel (as, for example, in candidate $(\mathrm{g})$ ) will violate *[-long,-stress][+stress]. Due to IDENT (back) (low) any vowels with features [+back] or [+low] will also be discarded. The ranking of MAX I-O over DEP I-O allows us to eliminate candidates (c) and (d). Candidate (e) is also eliminated by a faithfulness constraint against epenthesis, which makes (b) the optimal one, however not perfect since it also violates the lowest-ranked constraint of syllabic identity.

The proposed OT analysis of the most commonly applied repair strategies within sonorant + obstruent group, i.e. epenthesis and cluster modification, show that when native speakers of English encounter illicit CC consonant clusters of this segmental makeup, they rank SON-SEQ constraint higher than faithfulness constraints. Moreover, it demonstrates the reranking of these constraints by different speakers which results in the choice of different repair strategies.

As has been shown, an OT analysis successfully accounts for different types of adaptations employed by the participants of the experiment. However, depending on the type of clusters, the ranking of constraints may differ from speaker to speaker. Thus, in the case of word-initial CC consonant clusters of falling sonority, native speakers of English will rank higher the constraint prohibiting falling sonority in complex onsets. On the other hand, when the SSG is not violated by a cluster, another set of constraints will motivate the choice of a repair strategy.

\section{Conclusions}

The results of the experiment on the online adaptation of Ukrainian word-initial two-consonant clusters of opposite sonority demonstrate an interplay of a number of factors. First of all, the cluster's sonority profile influences the successful reproduction of illicit combinations. Clusters with raising sonority in the onset are reproduced more 
successfully than those with falling sonority. In the experiment $41 \%$ of such sequences were classified as target-like, while only $18 \%$ of those with falling sonority were produced by the participants correctly. The data demonstrate that those sequences that conform to the SSG do not pose as much of a pronunciation challenge to native speakers of English as those that violate this principle.

The cluster's segmental make-up should also be taken into account when making predictions about the preferred repair strategies of illicit sequences. The experiment has shown that fricative + sonorant combinations (e.g. /zl/, /zm/, /sr/) are reproduced faithfully more often than other obstruent + sonorant sequences, while epenthesis is more common in plosive + sonorant clusters (e.g. [gm-], [dn-]). The other factors to be considered are English phonotactic constraints such as, for example, the prohibition of coronal-coronal sequences, which resulted in frequent modification of $/ \mathrm{tl} /$ to $[\mathrm{pl}]$ (72\%), or the vocalisation of the palatal glide in $/ \mathrm{jt} /$ and $/ \mathrm{jm} /$ sequences by $64 \%$ and $52 \%$ of the participants respectively.

The application of OT principles in the analysis of the patterns discussed in this paper allowed us to account for them adequately. Different repair strategies can be attributed to different ranking of constraints employed by native speakers.

\section{References}

Brasington, R. 1997. Cost and benefit in loanword adaptation. Working Papers in Linguistics 3, 1-19.

Clements, G. N. 1990. The role of the Sonority Cycle in Core Syllabification. In: Kingston and Beckman (eds.) Laboratory Phonology 1, Cambridge: Cambridge University Press, 283-333.

Dupoux, E., Peperkamp, S. 2011. Where do illusory vowels come from? Journal of Memory and Language 64. 199-210.

Haunz, C. 2007. Factors in On-line Loanword Adaptation. PhD Dissertation. University of Edinburgh.

Hayes, B., Wilson, C. 2008. A Maximum Entropy Model of Phonotactics and Phonotactic Learning. Linguistic Inquiry, 39(3), 379-440.

Kager, R. 1999. Optimality Theory. Cambridge: Cambridge University Press. 
Kang, Y. 2011. Loanword phonology. In: M. van Oostendorp, C. J. Ewen, E. Hume and K. Rice (eds.), Companion to Phonology. Oxford: Blackwell, 2258-2282.

Lin, Y. 2005. Piro affricates: Phonological edge effets and phonetic anti-edge effects. In: M. van Oostendorp, J. van Weijer (eds.), The Internal Organization of Phonological Segments. Berlin: Mouton de Gruyter, 121-152.

McCarthy, J. J. 1986. OCP Effects: Gemination and Antigemination. Linguistic Inquiry 17. 207-263.

MacEachern, M. 1999. Laryngeal Co-occurrence Restrictions. New York: Garland.

McCarthy, J. J., Prince, A. 1995. Faithfulness and reduplicative identity. In: J. Beckman, L. W. Dickey, S. Urbanczyk (eds.), Papers in Optimality Theory. University of Massachusetts Occasional Papers 18. Amherst, Mass.: Graduate Linguistic Student Association, 249-384.

Paradis, C., LaCharite, D. 1997. Preservation and minimality in loanword adaptation. Journal of Linguistics 33, 379-430.

Peperkamp, S., Dupoux, E. 2003. Reinterpreting loanword adaptations: The role of perception. In: M. J. Solé, D. Recasens, J. Romero (eds.), Proceedings of the 15th International Congress of Phonetic Sciences. Barcelona: Causal Productions, 367370.

Radomski, M. 2014. Adaptation of Polish CC obstruent clusters by native speakers of English. In: E. Cyran, J. Szpyra-Kozłowska (eds.), Crossing Phonetics-Phonology Lines. Newcastle upon Tyne: Cambridge Scholars Publishing, 327-346.

Radomski, M., Sydorenko, K. 2016. Consonant deletion in online adaptation of Polish and Ukrainian consonant clusters by native speakers of English. In: J. Szpyra-Kozłowska, E. Cyran (eds), Phonology, its Faces and Interfaces. Frankfurt am Main: Peter Lang GmbH, 261-275.

Sievers, E. 1885. Grundzüge der Phonetik: zur Einführung in das Studium der Lautlehre der indogermanischen Sprachen, third ed. Cambridge: Breitkopf und Härtel.

Selkirk, E. O. 1984. On the major class features and syllable theory. In: M. Aronoff, R. Oerhle (eds.), Language Sound Structure. Cambridge: MIT Press, 107-136.

Steriade, D. 1982. Greek Prosodies and the Nature of Syllabification. PhD thesis. MIT.

Wells, J.G. 2008. Longman Pronunciation Dictionary ( $3^{\text {rd }}$ edition). Harlow: Pearson Education Limited. 